\title{
Investigations of biofilms formed on silica in contact with aqueous formulations containing laccase and maltodextrin
}

\author{
Yendry Regina Corrales Ureña ${ }^{1,2^{*}}$, Linda Gaetjen², Matheus Vieira Nascimento ${ }^{2,3}$, Paulo Noronha Lisboa Filho ${ }^{4}$, \\ Welchy Leite Cavalcanti ${ }^{2}$, Paul-Ludwig Michael Noeske ${ }^{2}$ and Klaus Rischka ${ }^{2}$
}

\section{${ }^{*}$ Correspondence:}

yendry386@hotmail.com

${ }^{1}$ Programa de

Pós-Graduação em Ciência

e Tecnologia de Materiais (POSMAT), São Paulo State University (UNESP), Av. Eng. Luiz Edmundo Carrijo Coube 14-01, Bauru, São Paulo 17033-360, Brazil

Full list of author information is available at the end of the article

\begin{abstract}
The formation of nano-scale biofilms on hydrophilic silica surfaces from aqueous polypeptide/polysaccharide mixtures containing laccase and maltodextrin was investigated in situ with quartz crystal microbalance with dissipation monitoring (QCM-D). Surface analysis techniques such as X-ray photoelectron spectroscopy (XPS), optically stimulated electron emission (OSEE) and atomic force microscopy (AFM) were applied for characterizing the resulting layers obtained after periods varying from a few seconds to several hours of contact between the substrate and the biopolymers formulation. The biofilm formation in contact with the aqueous laccase/maltodextrin suspension was studied at $\mathrm{pH}$ level 4.75 , under conditions close to the isoelectric point of the enzyme. The few nanometers rough biofilms obtained were composed of a laccase/maltodextrin mixture, and their thickness was observed to steadily increase during $4 \mathrm{~h}$ of contact with the aqueous mixture of biopolymers. Remarkably, the still adhesive films obtained after $1 \mathrm{~h}$ of contact with aqueous polypeptide/polysaccharide mixture resisted a 30 min rinsing with acetate buffer. The biofilms growing process was monitored using OSEE, due to the effected attenuation of the UV-induced electron emission from the $\mathrm{SiO}_{2} / \mathrm{Si}$ substrate, which was found to be more pronounced than the attenuation of the photoelectrons from the substrate which contribute to the XPS signals. Layers as thin as $1 \mathrm{~nm}$ were detected by the OSEE.
\end{abstract}

Keywords: Laccase maltodextrin mixture, Biopolymer adsorption, Adhesion of biofilms, Surface analysis and monitoring

\section{Background}

The protein adsorption on biomaterials, such as titanium alloys or surfaces of pharmaceutical vials as glass containers, is influenced by complex interactions implying the excipients in the protein based formulations [1-4]. In the case of pristine glass container surfaces the proteins are known to adsorb, lowering their concentration and reducing the availability of therapeutics in solution. Surfactants, polysaccharides and salts are added to pharmaceutical products to stabilize protein formulations and to avoid denaturalization and aggregation $[1,5,6]$. Understanding the biofilm formation upon contact with biopolymer mixture formulations on solid surfaces is essential for the design of a

\section{Springer}

(C) 2016 Corrales Ureña et al. This article is distributed under the terms of the Creative Commons Attribution 4.0 International License (http://creativecommons.org/licenses/by/4.0/), which permits unrestricted use, distribution, and reproduction in any medium, provided you give appropriate credit to the original author(s) and the source, provide a link to the Creative Commons license, and indicate if changes were made. 
biocompatible material surface that can inhibit or enhance protein adsorption, depending on the respective application [7].

The interaction of proteins or polypeptides with molecules such as polysaccharides is complex; aggregation and association processes observed in solution depend on the conditions of the media and on the ongoing surface-related processes such as cooperative adsorption, displacement and aggregation. In addition, bulk and surface interactions need to be considered $[8,9]$. In general, surface modification with mixtures containing surfactants and proteins have been extensively studied in solid/liquid interfaces [10] as well as the behavior of mixtures comprising proteins and polysaccharides at liquid/liquid interfaces as in water/oil emulsions [11].

The laccase enzymes (EC 1.10.3.2, p-diphenol:dioxygen oxidoreductase) are phenol oxidase enzymes and glycoproteins usually employed in degradation reactions of phenolic compounds, synthesis of organic compounds [12] and adhesive formulations [13]. The structure and behavior of multi-copper-oxidases in aqueous media using classical and quantum mechanical theories recently gained outstanding attention when it was highlighted as Fig. 1 in the scientific background on the Nobel prize in chemistry 2013, concerning the understanding complex chemical systems [14].

This study is focused on the interaction of an aqueous suspension of laccase and a polyssacharide with a hydrophilic surface. The polysaccharide maltodextrin was added as a stabilizing and a lyophilizating agent to laccase enzyme formulation [15]. The involved mode of action was suggested to be based on hydrogen bonding, with the hydroxyl groups of maltodextrin having a role firstly as a stabilizing agent in the solution [15], and secondly by replacing the water molecules lost upon drying the protein material [16]. Biofilms produced by the thus resulting protein/polysaccharide complexes are used in industry for production of food packaging, sutures, wound dressings or for protein-carbohydrates based adhesives [17, 18], mainly because of their favorable cohesive and adhesive properties as well as their biodegradability and environmental safety [19] [20]. On the other hand, polysaccharides, such as dextrans, are used to avoid protein

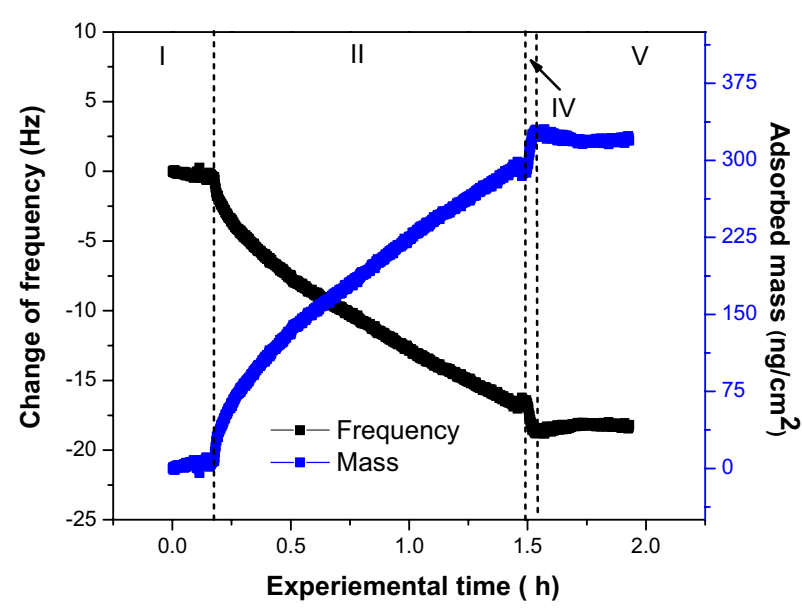

Fig. 1 Results of frequency changes during QCM-D measurements as a function of experimental time. Silica coated QCM-D crystals in contact with $0.2 \mathrm{M}$ aqueous sodium acetate buffer (stage I), with $0.1 \mathrm{mg} / \mathrm{ml}$ laccase mixture suspension (stage II), and finally rinsing with $0.2 \mathrm{M}$ aqueous sodium acetate buffer (stages IV and V) 
adsorption on biomedical devices, such as contact lenses and artificial blood vessels [21]. The anti-adhesion properties are related to the reduction of the interfacial energy, the large exclusion volume or influences on the system entropy impacted by the heavily solvated, the neutral and randomly oriented polymer chain and the sterical impediment, being similar to the effect of polyethylene glycol films [21-24]. However, adhesive properties also depend on the surface roughness of the adsorbent, the protein carbohydrate combination [25] or factors such as $\mathrm{pH}$ and ionic strength in the liquid phase [26, 27]. Therefore, the adsorption behavior is characteristic for each singular protein, and computer-based simulation may permit recommending trends or development directions [28]. For example, albumin adsorbs on both hydrophobic and hydrophilic surfaces, even if the polarity of charges on the protein and the surface is the same, whereas ribonuclease is reported to adsorb on hydrophobic surfaces under all conditions of charge, but to adsorb on hydrophilic surfaces only if the interaction is electrostatically favored [29].

In the present study, the layer formation from polypeptide/polysaccharide mixtures containing laccase and maltodextrin on hydrophilic $\mathrm{Si} / \mathrm{SiO}_{2}$ surfaces was investigated. The biofilm formation in contact with the aqueous laccase/maltodextrin suspension was studied with a $\mathrm{pH}$ value of 4.75 , under conditions close to the isoelectric point of the enzyme, where a low electrostatic repulsion between protein molecules and neighboring protein or polysaccharide molecules may be expected. Therefore, in a $\mathrm{pH}$ where the enzyme is stable [30] and their higher catalytic activity [31].

Quartz crystal microbalance with dissipation monitoring (QCM-D), X-ray photoelectron spectroscopy (XPS), optically stimulated electron emission (OSEE) and atomic force microscopy (AFM) were applied for characterizing the adsorptive growth of the biofilm on the surface.

\section{Methods}

\section{Laccase mixture suspension}

Acetic acid and sodium acetate were used as grade reagents (Sigma-Aldrich). A laccase mixture suspension (concentration $0.1 \mathrm{mg} / \mathrm{ml}$ ) was prepared with laccase from a Trametes versicolor/maltodextrin powder mixture (ASA Spezialenzyme GmbH, Wolfenbüttel, Germany) in $0.2 \mathrm{M}$ aqueous acetate buffer, $\mathrm{pH}$ value 4.75 . The suspension was prepared using deionized water and aseptic conditions at $25^{\circ} \mathrm{C}$. These same preparation conditions were used for the QCM-D experiment and for the preparation of $\mathrm{SiO}_{2} /$ Si substrates.

\section{Preparation of laccase/silica samples}

Silicon wafer with a native oxide layer $\mathrm{SiO}_{2} / \mathrm{Si}(100)$ were used as a substrate. The laccase mixture suspension was pipetted onto the substrate surface. After the respective contact time (with times varying between $10 \mathrm{~s}$ and $4 \mathrm{~h}$ ), the surface was rinsed gently for some seconds with deionized water, followed by blowing with air. Finally, the samples were allowed to dry and were stored under environmental conditions at room temperature.

\section{Qcm-d}

Quartz crystal microbalance with dissipation monitoring (QCM-D E4, Q-Sense, Sweden) was to evaluate the adsorption from aqueous laccase mixture suspension on silica 
coated QCM-D sensors. The flow rate was $100 \mu \mathrm{L} / \mathrm{min}$ and the temperature was maintained constant at $25{ }^{\circ} \mathrm{C}$. The sensors were mounted in the flow modules and the system was equilibrated with buffer for $30 \mathrm{~min}$ to generate a stable baseline. Then, the aqueous laccase mixture suspension was flushed over the silica crystals. The changes in the frequency (f), related to the attached mass (including coupled water), and the changes in dissipation (D), related to the frictional (viscous) properties of the adsorbed laccase layer, were recorded using QSoft ${ }^{\mathrm{TM}}$ control software (Q-Sense, Sweden). More details of the experimental procedure was described by Corrales et al. [30].

\section{X-ray photoelectron spectroscopy}

XPS spectra were taken using a Kratos Ultra facility and applying the following acquisition parameters: base pressure: $4^{*} 10^{-8} \mathrm{~Pa}$, sample neutralization applying low energy electrons $(<5 \mathrm{eV})$, hybrid mode (electrostatic and magnetic lenses are used), take off angle of electrons $0^{\circ}$, pass energy $20 \mathrm{eV}$ (or, respectively, $40 \mathrm{eV}$ in the case of most $\mathrm{N} 1 \mathrm{~s}$ spectra) in high resolution spectra and $160 \mathrm{eV}$ in survey spectra, excitation of photoelectrons by monochromatic $\mathrm{Al} \mathrm{K}_{\alpha}$ radiation. The analysis area was elliptically shaped with main axes of $300 \times 700 \mu \mathrm{m}$. The thus obtained information depth is approximately $10^{-8} \mathrm{~m}$.

\section{Atomic Force Microscopy AFM}

The sample topography and local material properties were approached using a scanning force microscope (SFM) (Digital Instruments Nanoscope III multimode SPM) operated in the 'tapping mode' in air, using the scanner with ser. no. 6965JVH and Nanoscope software (Version 5.31R1) for acquiring height and phase images. Si Sensors (model Veeco OTESPA made from $1 \mathrm{Ohm}$ Silicon; back side of the cantilever covered with $50 \mathrm{~nm} \mathrm{Al}$ coating) with resonance frequencies of $12-103 \mathrm{kHz}$ were used. For characterizing structures of adsorbates, among other criteria, height differences were evaluated. In detail, the particle height was obtained by evaluating the vertical distance between the top of a particle and the slightly rough base area below the base-line separated particles. The root mean square (RMS) roughness was obtained calculating the average of three different areas using the software Nanoscope Analysis Bruker.

\section{Optically stimulated electron emission (OSEE)}

For the OSEE experiments a surface quality monitor SQM300 (Photo Emission Tech., Inc. (PET), USA) was used. Under ambient conditions the sample surface is exposed to ultra-violet light from a mercury vapor lamp (emission maxima 4.9 and $6.7 \mathrm{eV}$.). The device contains a solid state electrometer capable of measuring emitted photoelectrons from the tested samples. Those photoelectrons flow through a collector (adjusted at $+40 \mathrm{~V}$ ), generating a current and its intensity is denoted as the OSEE intensity. The device features an earthed moving table on which the samples are scanned in orthogonal directions within a few millimeters distance to the UV lamp. The OSEE signal values presented in this work were obtained by calculating the average of the OSEE intensities from the center of the samples. 


\section{Experimental results and discussions}

In this chapter, first the in situ experiments focusing on the adsorption from the aqueous biopolymer formulation on silica surfaces are detailed. Subsequently, the ex situ characterization of the biofilms by spectroscopic and microscopic techniques will be reported.

\section{Qcm-d}

Following the layer formation in situ by QCM-D, Fig. 1 shows the mass uptake related to the changes in oscillation frequency of the silica substrates related to the absorbates getting attached from the laccase-maltodextrin suspension. As described in the experimental section, firstly the pure acetate buffer solution was flushed over the crystal surface (baseline), stage I, followed by a contact-period with the laccase-maltodextrin suspension, stage II. In stage II a decrease of the frequency indicates mass adsorption. A steady state was not achieved after one and a half hours of contact with the suspension. The slow decrease in the frequency was observed in the early stages of biofilm growth on the silica substrate and, later on, on top of the already formed biofilm as suggested by the results of AFM investigations presented in the next section. Such small growth rate might be considered an indicative of a low affinity of the biopolymers for adsorption to the surface. A steady state, stage III, was not achieved during the contact time, as it will be presented in further studies by the authors. In stage IV and V the surface was flushed with the buffer for $30 \mathrm{~min}$ and only low desorption of the biofilm in the early stage IV was detected. The insignificant extent of desorption of the surface is related to a surprisingly stable layer formation.

The mass adsorbed was calculated using Sauerbrey equation due to the low changes in dissipation [32] (data not shown). The layer thickness of $2.3 \mathrm{~nm}$ reached after $74 \mathrm{~min}$ of contact was calculated having as reference the density of a hydrated protein layer of $1.3 \mathrm{~g} / \mathrm{cm}^{3}$ [33], the experimentally observed mass value of $320 \mathrm{ng} / \mathrm{cm}^{2}$ and assuming an homogeneous surface coverage.

\section{Atomic force microscopy (AFM)}

The rinsed and dried layers formed were imaged after contact with the laccase mixture suspension for periods between $1 \mathrm{~min}$ and $4 \mathrm{~h}$. The measured AFM topography images are shown in Fig. 2, and the obtained RMS roughness values are listed in Table 1 together with an evaluation of the average particle heights. These findings indicate that the steadily ongoing adsorption is accompanied by the formation of particulate adsorbates with increasing heights. After 1 min of contact time, particles with heights of 2.6 and $3.9 \mathrm{~nm}$ were imaged. Following the QCM-D results, that base essentially may be attributed to the substrate surface, and XPS investigations will contribute to verifying this interpretation. After $10 \mathrm{~min}$ of contact time, the average lateral distances between smaller particles with heights around $2.6 \mathrm{~nm}$ were smaller than after $1 \mathrm{~min}$ of contact time. This finding indicates an ongoing adsorption of particulate biopolymer material on the $\mathrm{SiO}_{2} / \mathrm{Si}$ substrate surface during the first ten minutes of contact with the laccase/maltodextrin mixture suspension. After one hour mainly particle heights around $6.2 \mathrm{~nm}$ were imaged. After $4 \mathrm{~h}$ of contact, the area density and the height of the particles increased, suggesting an adsorption or aggregation on the top of the previously adsorbed biopolymers. 


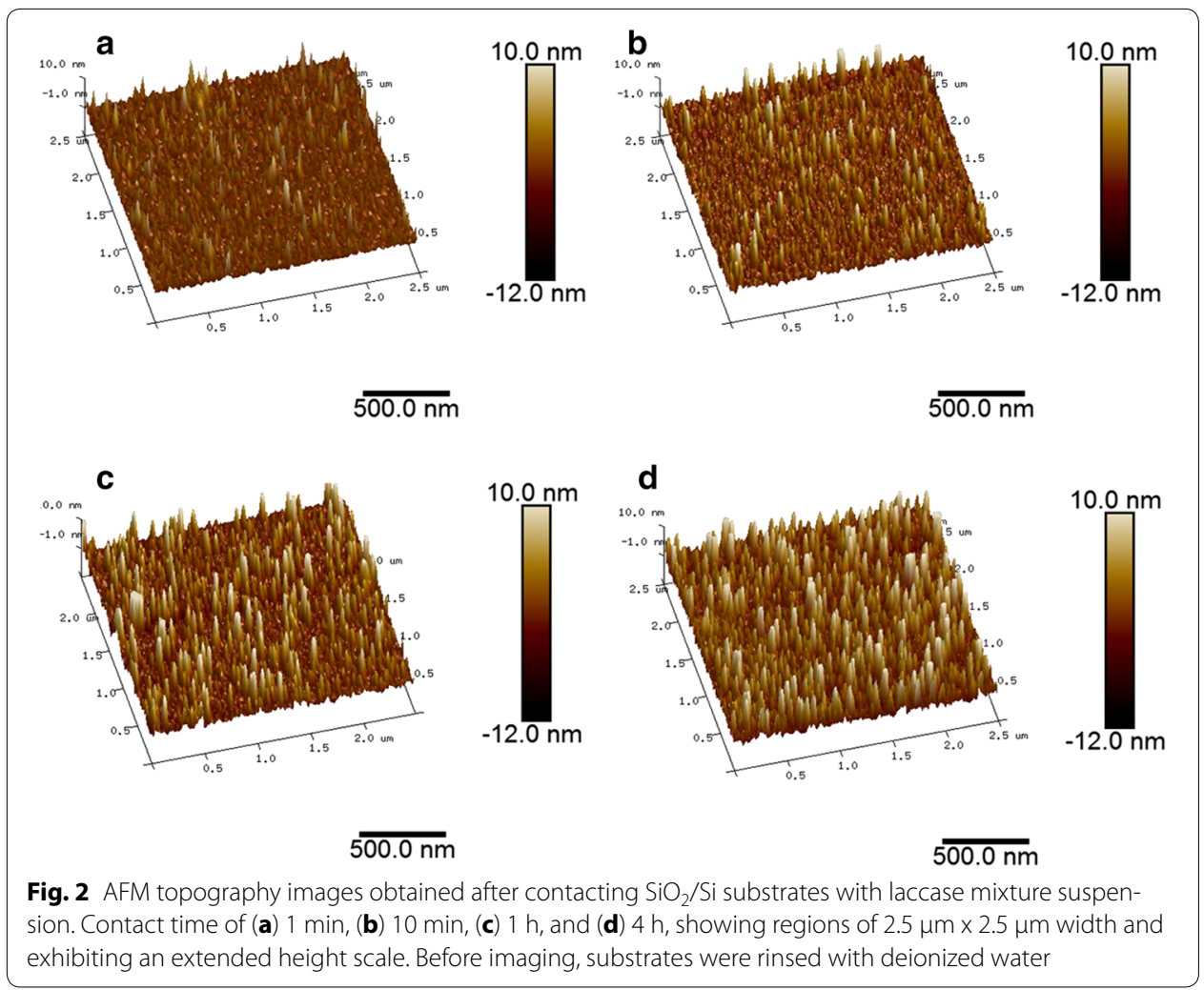

Table 1 Evaluation of the AFM results obtained when increasing the contact time between $\mathrm{SiO}_{2} / \mathrm{Si}$ substrates and aqueous laccase/maltodextrin mixture suspensions

\begin{tabular}{llc}
\hline Contact time & $\begin{array}{l}\text { Root mean square } \\
\text { (RMS) roughness }\end{array}$ & Particle height $(\mathbf{n m})$ \\
\hline $0 \mathrm{~s}$ & $0.4 \pm 0.1 \mathrm{~nm}$ & - \\
$1 \mathrm{~min}$ & $1.3 \pm 0.1 \mathrm{~nm}$ & $2.6 \pm 1.4$ \\
& & $3.9 \pm 1.5$ \\
$10 \mathrm{~min}$ & $1.7 \pm 0.1 \mathrm{~nm}$ & $2.8 \pm 0.2$ \\
& & $6.7 \pm 0.7$ \\
$1 \mathrm{~h}$ & $2.6 \pm 0.3 \mathrm{~nm}$ & $6.2 \pm 0.7$ \\
$4 \mathrm{~h}$ & $2.8 \pm 0.2 \mathrm{~nm}$ & $8.6 \pm 0.7$ \\
\hline
\end{tabular}

These observations coincide with the increase of the RMS roughness values (RMS) of the biofilms with increasing contact time. This finding is associated with biopolymer adsorption.

Figure 1 stage IV and Fig. 2c shows that the layer was stable and that could not be easily rinsed away after buffer rinsing.

A more detailed AFM top view image and smaller width than shown in Fig. 2a is presented in Fig. 3. Moreover, a cross-section image is shown. The image shows up to $6 \mathrm{~nm}$ high particulate elevations, yielding a particle density around 925 particles $/ \mu \mathrm{m}^{2}$. Such particulate adsorbates may be related to the biopolymers in the laccase/maltodextrin mixture suspension. Laccases are globular proteins and therefore they present a spherical morphology in a nanometer size. Conformational changes of these molecules are 

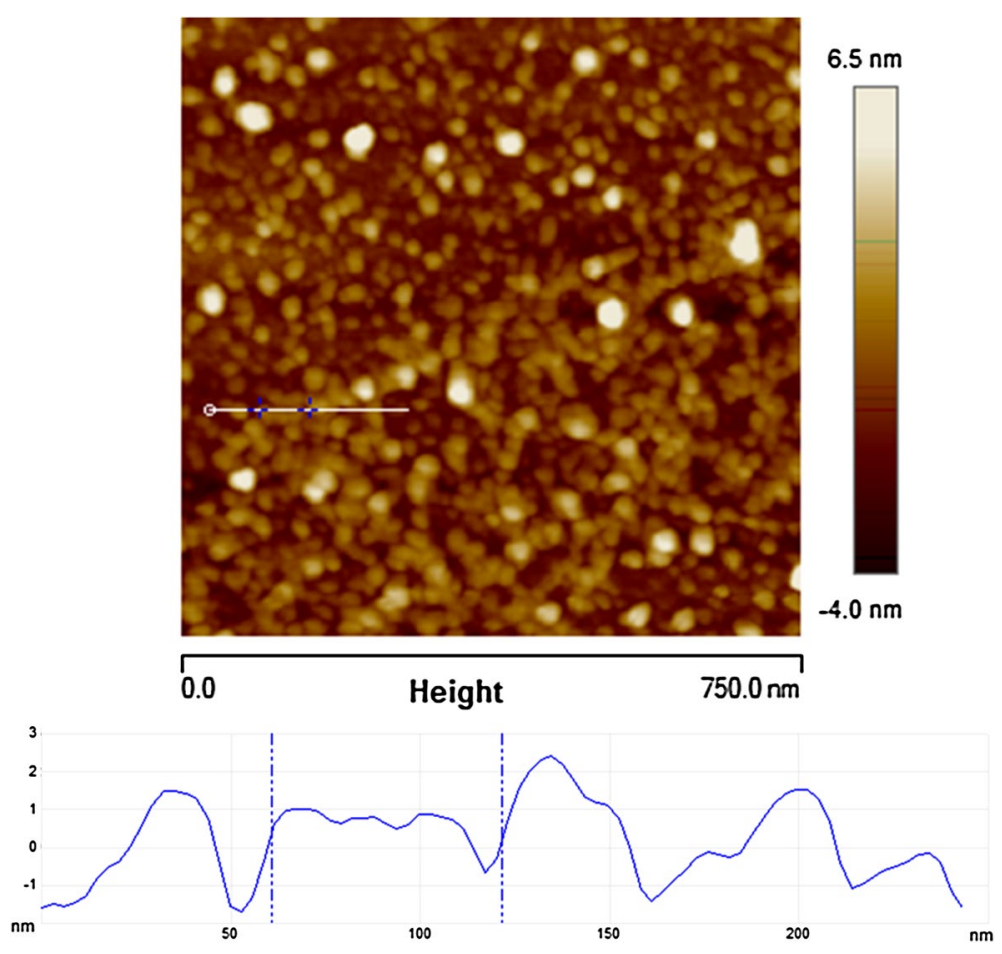

Fig. 3 AFM height and cross section image of $750 \mathrm{~nm} \times 750 \mathrm{~nm}$ width image. $\mathrm{SiO}_{2} / \mathrm{Si}$ substrate in contact for 1 min with the laccase mixture suspension. Before imaging, the substrate was rinsed with deionized water

mostly expected due to the adsorption on hydrophobic surfaces [34]. On hydrophilic surfaces, globular proteins were reported to maintain their morphology to a certain degree, which is characteristic in liquid formulations [29]. Considering that González Arzola et al. reported the height of $2.5 \mathrm{~nm}$ laccase monomers on HOPG and on gold approximately 5-6 $\mathrm{nm}$ [35], the observed particles with heights of 3.9 or $2.6 \mathrm{~nm}$ could be associated with the adsorbed laccase enzyme, depending on the surface orientation and degree of denaturation. However, the roundish nanometer features may also be associated to complexes and aggregates of both biopolymers present in the aqueous mixture. Concerning possible interpretations of the material composition of the particles and the regions between them, we point out that the adsorption behavior of proteins, such as fibrinogen on hydrophilic hydroxyl terminate surface, was shown to be complex [36], and in case of applying mixtures of biopolymers the complexity may be expected to be even higher.

Consequently, in order to determine if the adsorbates imaged on the $\mathrm{SiO}_{2} / \mathrm{Si}$ surface be identified as laccase, laccase-maltodextrin or maltodextrin, the chemical composition was investigated by XPS. Table 2 shows the results of the elemental surface composition when varying the time of contact between the $\mathrm{SiO}_{2} / \mathrm{Si}$ substrate and the mixture suspension. For comparison, the composition of the used laccase-maltodextrin powder and, moreover, the composition of a purified laccase powder are shown.

For revealing the time-dependence of the adsorbate composition and the substrate coverage, the XPS results are displayed in Fig. 4. In detail, Fig. 4a shows the increase in the nitrogen surface concentration $[\mathrm{N}]$ with contact time. This concentration can be 
Table 2 Elemental surface composition after contact of $\mathrm{SiO}_{2} / \mathrm{Si}$ substrates with aqueous laccase mixture suspension

\begin{tabular}{lllllll}
\hline Time in contact & [Si] (at \%) & [O] (at \%) & [C] (at \%) & [N] (at \%) & [Na] (at \%) & [N]/[C] \\
\hline 0 & 59.5 & 35.3 & 7.6 & 0.1 & 0 & 0.01 \\
$10 \mathrm{~s}$ & 56.7 & 32 & 10.7 & 0.6 & $<0.1$ & 0.06 \\
$1 \mathrm{~min}$ & 55.9 & 31.3 & 12.1 & 0.7 & $<0.1$ & 0.06 \\
$10 \mathrm{~min}$ & 51.8 & 31.6 & 15.4 & 1.1 & $<0.1$ & 0.07 \\
$1 \mathrm{~h}$ & 43.4 & 29.1 & 23.6 & 3 & 0.8 & 0.13 \\
$4 \mathrm{~h}$ & 38.8 & 28 & 28.4 & 3.8 & 1 & 0.14 \\
Purified laccase powder & - & 22.4 & 65.0 & 11.3 & 0.3 & 0.20 \\
Laccase-maltodextrin powder mixture & - & 27.3 & 66.5 & 5.4 & 0.3 & 0.08 \\
\hline
\end{tabular}

XPS results, given in atom \% (at \%), for times varying between $10 \mathrm{~s}$ and $4 \mathrm{~h}$, and for laccase-containing powders

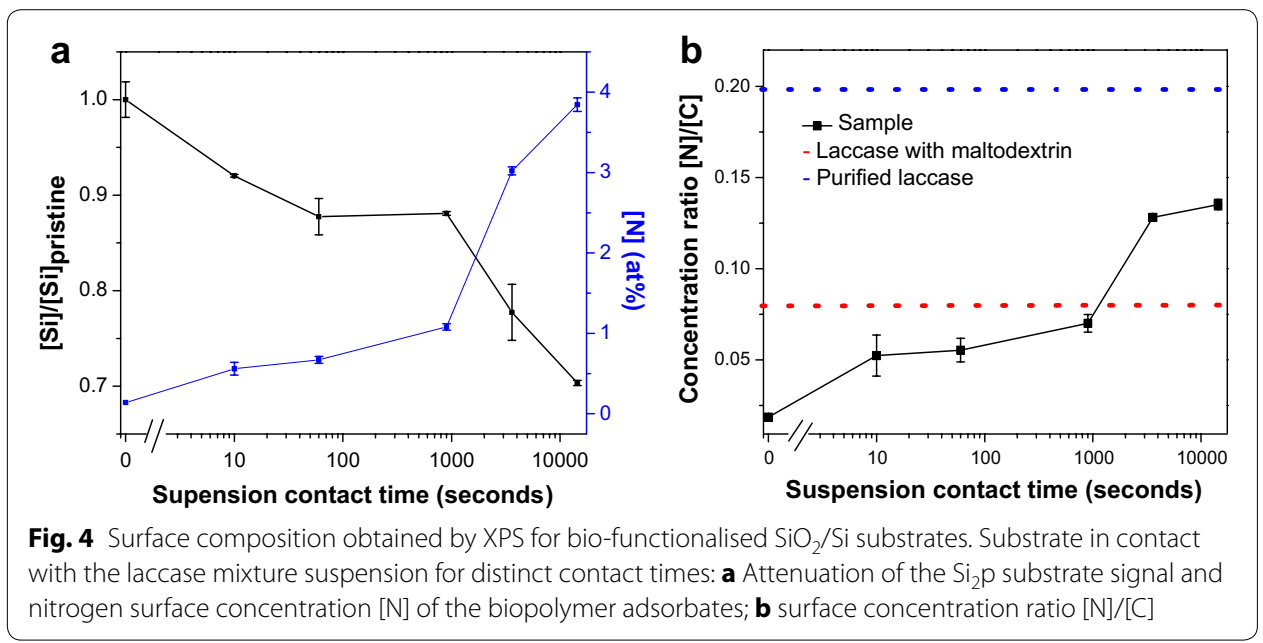

used as a qualitative and even as a quantitative marker for protein adsorption. The higher increase was detected between $1 \mathrm{~min}$ and $1 \mathrm{~h}$. After $1 \mathrm{~h}$ a steady state is suggested by the low changes in $[\mathrm{N}]$. Also as shown by AFM the increase in density of particles with height of $3.9 \mathrm{~nm}$ on the surface. Figure $4 \mathrm{~b}$ shows the $[\mathrm{N}] /[\mathrm{C}]$ surface concentration ratio. In the first $10 \mathrm{~min}$ this ratio shows similar values as the powder containing a laccasemaltodextrin mixture. However, after $1 \mathrm{~h}$ the ratio shows similar values as compared to the laccase purified. The results therefore suggest that the layer formed on $\mathrm{the}_{\mathrm{SiO}_{2}} / \mathrm{Si}$ surface is a mixture of the laccase-maltodextrin and a coadsorption of these biopolymers may be assumed based on the feasible molecular interactions.

The layer thickness of the dry film may be calculated based on the XPS results obtained if a geometric model for the adsorbate structure is assumed. Following the data presented by Seah and Fritz, the inelastic mean free path (IMFP) of $\mathrm{Si}_{2} \mathrm{p}$ electrons in an organic adsorbate layer is $3.2 \mathrm{~nm}$. Assuming a flat, smooth, homogeneous organic layer to be formed after $4 \mathrm{~h}$, a layer thickness of $1.2 \mathrm{~nm}$ might be expected. However, such thickness is lower than the roughness of the layer as observed by AFM measurements. Thus, the layer thickness will be underestimated.

As the presented investigations by QCM-D, AFM and XPS indicate an ongoing adsorbate layer growth during at least $4 \mathrm{~h}$ of contact between the hydrophilic $\mathrm{SiO}_{2} / \mathrm{Si}$ 


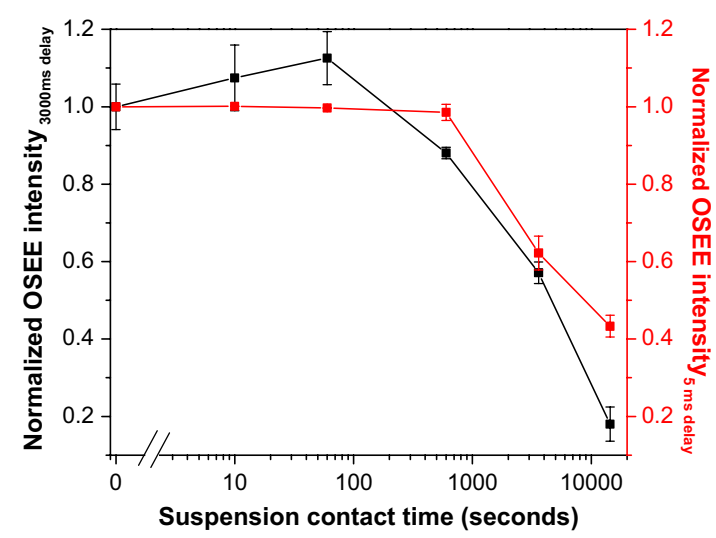

Fig. 5 OSEE signal as a function of time in contact with the laccase mixture suspension. Substrates rinsed with deionized water

and the aqueous laccase/maltodextrin mixture suspension, a fast analysis of the obtained biofilm may be aspired when aiming at surface quality assurance of the bio-functionalization process. In this regard, OSEE investigations in air were performed. Figure 5 displays the normalized OSEE intensity for native $\mathrm{SiO}_{2} / \mathrm{Si}$ substrates and substrates covered with a biofilm after various times of contact with the laccase mixture suspension. The OSEE signals were read for two delay times (3000 and $5 \mathrm{~ms}$ ) set as measurement parameters, with the delay time representing the period between moving the scanned sample to a subsequent position below the OSEE sensor and measuring the OSEE intensity. A clear decrease of the signal intensity was observed when the $\mathrm{SiO}_{2} / \mathrm{Si}$ substrates were immersed for 1 or $4 \mathrm{~h}$. When optimising the delay time parameter with respect to differentiating even thinner biofilms, setting a delay time of $3000 \mathrm{~ms}$ permitted obtaining a distinct OSEE signal even for the sample resulting from $10 \mathrm{~min}$ of contact with the suspension. Thus, using OSEE inspection the thickness of the dried biofilms can be monitored even for films as thin as $1 \mathrm{~nm}$. The observed decrease of the OSEE intensity as a consequence of the biofilm covering the $\mathrm{SiO}_{2} / \mathrm{Si}$ substrate is attributed to the attenuation of the UV-induced electron emission from the $\mathrm{SiO}_{2} / \mathrm{Si}$ substrate. Comparing the effect of increasing the suspension contact time on the normalized OSEE intensity as displayed in Fig. 5 with the respective effect on the $[\mathrm{Si}] /[\mathrm{Si}]_{\text {pristine }}$ XPS signal ratio shown in Fig. 4a, it becomes evident that the same biofilm affects a more pronounced substrate attenuation in OSEE investigations than in XPS investigations. This is attributed to a higher surface sensitivity of OSEE as compared to XPS measurements.

\section{Conclusions and outlook}

This work presented results obtained with in situ and ex situ surface analyses illustrate the biofilm formation on silica-based surfaces from a biopolymer mixture suspension composed by a glycoprotein and a polysaccharide. The protein and the polysaccharide are revealed to coadsorb on the surface forming a mixed nanolayer exhibiting particulate adsorbates. Concerning projected applications of the findings, the laccase/maltodextrin mixture suspension might be used for the bio-functionalization of technical surfaces, and for tuning the adhesive properties of these surfaces. On the other hand, glass surface 
modifications may be tested with respect to their effectivity using the contact with standardized laccase-maltodextrin mixtures.

\section{Author's contributions}

YCU planned and performed AFM investigations, drafted the manuscript; LG conducted the measurements and interpretation of the QCM-D data. MV planned OSEE experiments under the surpervision of PLN and performed sample preparation; PLN performed OSEE and XPS measurements and evaluated them; PNL provided information about technological boundary conditions of the surface pre-treatment and technological challenges; WL participated in the identification of the research topic, the conception of the investigations and drafting the manuscript; KR participated in the identification of the research topic, the conception of the investigations and drafting the manuscript. All authors read and approved the final manuscript.

\section{Author details}

${ }^{1}$ Programa de Pós-Graduação em Ciência e Tecnologia de Materiais (POSMAT), São Paulo State University (UNESP), Av. Eng. Luiz Edmundo Carrijo Coube 14-01, Bauru, São Paulo 17033-360, Brazil. ${ }^{2}$ Fraunhofer Institute for Manufacturing Technology and Advanced Materials (IFAM), Wiener Straße 12, 28359 Bremen, Germany. ${ }^{3}$ Federal University of Ceará, Av. Da Universidade 2853, Fortaleza, Ceará 60020-181, Brazil. ${ }^{4}$ São Paulo State University (UNESP), Av. Eng. Luiz Edmundo Carrijo Coube 14-01, Bauru, São Paulo 17033-360, Brazil.

\section{Acknowledgements}

The authors thank to Science without Borders (Ciência sem Fronteiras, proc: 88888.015774/2013-00,88888.020073/201300), Consejo Nacional para Investigaciones Científicas y Tecnológicas de Costa Rica (CONICIT) and FAPESP 2013/07296-2 for the funding. We heartily thank to Prof. Dr. Bernd Mayer, Dr. Ingo Grunwald and to Prof. Dr. Andreas Hartwig for the support.

\section{Competing interests}

The authors declare that they have no competing interests.

Received: 30 November 2015 Accepted: 1 February 2016

Published online: 12 February 2016

\section{References}

1. Wendorf JR, Radke CJ, Blanch HW. Reduced protein adsorption at solid interfaces by sugar excipients. Biotechnol Bioeng. 2004;87:565-73. doi:10.1002/bit.20132.

2. Coen MC, Lehmann R, Gröning P, Bielmann M, Galli C, Schlapbach L. Adsorption and bioactivity of protein A on silicon surfaces studied by AFM and XPS. J Colloid Interface Sci. 2001;233:180-9. doi:10.1006/jcis.2000.7240.

3. Höger K, Mathes J, Frieß W. IgG1 Adsorption to siliconized glass vials-influence of pH, ionic strength, and nonionic surfactants. J Pharm Sci. 2014;104:34-43. doi:10.1002/jps.24239.

4. Wu CC, Chen G. Adsorption of proteins onto glass surfaces and its effect on the intensity of circular dichroism spectra. Anal Biochem. 1989;177:178-82. doi:10.1016/0003-2697(89)90036-5.

5. Kim HL, Mcauley A, Mcguire J. Protein effects on surfactant adsorption suggest the dominant mode of surfactantmediated stabilization of protein. J Pharm Sci. 2014;103:1337-45. doi:10.1002/jps.23908.

6. Eu B, Cairns A, Ding G, Cao X, Wen Z. Direct visualization of protein adsorption to primary containers by gold nanoparticles. J Pharm Sci. 2011;100:1663-70. doi:10.1002/jps.22410.

7. Meißner RH, Wei G, Ciacchi LC. Estimation of the free energy of adsorption of a polypeptide on amorphous $\mathrm{SiO}_{2}$ from molecular dynamics simulations and force spectroscopy experiments. Soft Matter. 2015;11:6254-65. doi:10.1039/c5sm01444a.

8. Rabe M, Verdes D, Seeger S. Understanding protein adsorption phenomena at solid surfaces. Adv Colloid Interface Sci. 2011;162:87-106. doi:10.1016/j.cis.2010.12.007.

9. Ghosh AK, Bandyopadhyay P. Polysaccharide-protein interactions and their relevance in food colloids. In: Karunaratne DN, editor. The complex world of polysaccharides, vol. 14. InTech; 2012. p. 395-406. doi:10.5772/50561.

10. Frazier R, Matthijs G, Davies M, Roberts C, Schacht E, Tendler S. Characterization of protein-resistant dextran monolayers. Biomaterials. 2000;21:957-66. doi:10.1016/S0142-9612(99)00270-7.

11. Krafft M, Riess J. Highly fluorinated amphiphiles and colloidal systems, and their applications in the biomedical field. A contribution. Biochimie. 1998;80:489-514. doi:10.1016/S0300-9084(00)80016-4.

12. Riva S. Laccases: blue enzymes for green chemistry. Trends Biotechnol. 2006;24:219-26. doi:10.1016/j. tibtech.2006.03.006.

13. Butler JE. Solid supports in enzyme-linked immunosorbent assay and other solid-phase immunoassays. Methods. 2000;22:4-23. doi:10.1006/meth.2000.1031.

14. The Nobel Prize in Chemistry 2013-Advanced Information, Nobelprize.org. Nobel Media AB 2014. Web. Accessed on 18 Nov 2015 via <http://www.nobelprize.org/nobel_prizes/chemistry/laureates/2013/advanced.html>.

15. Dickinson E. Mixed biopolymers at interfaces: competitive adsorption and multilayer structures. Food Hydrocolloids. 2011;25:1966-83. doi:10.1016/j.foodhyd.2010.12.001.

16. Carpenter JF, Chang BS, Garzon-Rodriguez W, Randolph TW. Rational design of stable lyophilized protein formulations: theory and practice. In: Borchardt RT, Carpenter JF, Manning MC, editors. Rational design of stable protein formulations. Boston: Springer; 2002. p. 109-33. doi:10.1007/978-1-4615-0557-0_5.

17. Chen N, Lin Q, Rao J, Zeng Q. Water resistances and bonding strengths of soy-based adhesives containing different carbohydrates. Ind Crops Prod. 2013;50:44-9. doi:10.1016/j.indcrop.2013.06.038. 
18. Graham LD, Glattauer V, Huson MG, Maxwell JM, Knott RB, White JW, et al. Characterization of a protein-based adhesive elastomer secreted by the Australian frog Notadenbennetti. Biomacromolecules. 2005;6:3300-12. doi:10.1021/ bm050335e.

19. Pankratov D, Sotres J, Barrantes A, Arnebrant T, Shleev S. Interfacial behavior and activity of laccase and bilirubin oxidase on bare gold surfaces. Langmuir. 2014;30:2943-51. doi:10.1021/la402432q.

20. Dickinson E. Interfacial structure and stability of food emulsions as affected by protein-polysaccharide interactions. Soft Matter. 2008;4:932. doi:10.1039/B718319D.

21. McArthur SL, MCLean KM, Kingshott P, St John HA, Chatelier RC, Griesser HJ. Effect of polysaccharide structure on protein adsorption. Colloids Surf B. 2000;17:37-48. doi:10.1016/S0927-7765(99)00086-7.

22. Österberg E, Bergström K, Holmberg K, Riggs JA, van Alstine JM, Schuman TP, et al. Comparison of polysaccharide and poly(ethylene glycol) coatings for reduction of protein adsorption on polystyrene surfaces. Colloids Surf A. 1993;77:159-69. doi:10.1016/0927-7757(93)80112-R.

23. Piehler J, Brecht A, Hehl K, Gauglitz G. Protein interactions in covalently attached dextran layers. Colloids Surf B. 1999;13:325-36. doi:10.1016/S0927-7765(99)00046-6.

24. McLean KM, Johnson G, Chatelier RC, Beumer GJ, Steele JG, Griesser HJ. Method of immobilization of carboxymethyl-dextran affects resistance to tissue and cell colonization. Colloids Surf B. 2000;18:221-34. doi:10.1016/ S0927-7765(99)00149-6.

25. Tirrell M, Kokkoli E, Biesalski M. The role of surface science in bioengineered materials. Surf Sci. 2002;500:61-83. doi:10.1016/S0039-6028(01)01548-5.

26. Luey J, Mcguire J, Sproull RD. The effect of $\mathrm{pH}$ and $\mathrm{NaCl}$ concentration on adsorption of $\beta$-lactoglobulin at hydrophilic and hydrophobic silicon surfaces. J Colloid Interface Sci. 1991;143:489-500. doi:10.1016/0021-9797(91)90282-D.

27. Schmitt C, Sanchez C, Desobry-Banon S, Hardy J. Structure and technofunctional properties of protein-polysaccharide complexes: a review. Crit Rev Food Sci Nutr. 1998;38:689-753. doi:10.1080/10408699891274354

28. Cavalcanti WL, Noeske PM. Investigating dynamic interactions by multi-scale modelling: from theory to applications. In: Springborg M, Joswig J, editors. Chemical Modelling. Cambridge: Royal Society of Chemistry; 2014. p. 175-200. doi:10.1039/9781782620112-00175.

29. Norde W. Adsorption of proteins from solution at the solid-liquid interface. Adv Colloid Interface Sci. 1986;25:267340. doi:10.1016/0001-8686(86)80012-4.

30. Kurniawati S, Nicell J. Characterization of Trametes versicolor laccase for the transformation of aqueous phenol. Bioresour Technol. 2008;99:7825-34.

31. Majcherczyk A, Johannes C, Huttermann A. Oxidation of polycyclic aromatichydrocarbons (PAH) by laccase of Trametes versicolor. Enzyme Microbial Technol. 1998;22:335-41.

32. Castner DG, Ratner BD. Biomedical surface science: foundations to frontiers. Surf Sci. 2002;500:28-60. doi:10.1016/ S0039-6028(01)01587-4.

33. Armanious A, Aeppli M, Sander M. Dissolved organic matter adsorption to model surfaces: adlayer formation, properties, and dynamics at the nanoscale. Environ Sci Technol. 2014;48:9420-9. doi:10.1021/es5026917.

34. Corrales Ureña YR, Wittig L, Vieira Nascimento M, Faccioni JL, Lisboa Filho PN, Rischka K. Influences of the pH on the adsorption properties of an antimicrobial peptide on titanium surfaces. Appl Adhesion Sci. 2015;3:115. doi:10.1186/ s40563-015-0032-6.

35. Vörös J. The density and refractive index of adsorbing protein layers. Biophys J. 2004;87:553-61. doi:10.1529/ biophysj.103.030072.

36. Roach P, Farrar D, Perry CC. Interpretation of protein adsorption: surface-induced conformational changes. J Am Chem Soc. 2005;127:8168-73. doi:10.1021/ja0428980.

\section{Submit your manuscript to a SpringerOpen ${ }^{\circ}$ journal and benefit from:}

- Convenient online submission

- Rigorous peer review

- Immediate publication on acceptance

- Open access: articles freely available online

- High visibility within the field

- Retaining the copyright to your article

Submit your next manuscript at $>$ springeropen.com 